\title{
Should we take patients to hospital in cardiac arrest?
}

Bruce D Adams says that rules for deciding when to stop resuscitation are fallible, but Jonathan Benger argues that ambulance crews are best placed to deliver immediate cardiopulmonary resuscitation, which is usually the only treatment available

\section{Bruce D Adams chair and professor of emergency medicine ${ }^{1}$, Jonathan Benger professor of emergency care and consultant ${ }^{23}$}

${ }^{1}$ University of Texas Health Sciences Center San Antonio, 7703 Floyd Curl Drive, Mail Code 7736, San Antonio, Texas, USA 78229; ${ }^{2}$ University of the West of England, Bristol; ${ }^{3}$ University Hospitals Bristol NHS Foundation Trust

\section{Yes-Bruce D Adams}

Out of hospital cardiac arrest is a leading cause of premature death, and overall long term survival is about $10 \% .^{1}$ Two schools of thought towards cardiopulmonary resuscitation (CPR) have emerged in the past decade: the "glass $90 \%$ empty" sceptics, who see one arresting patient after another "come in dead and stay dead," versus the "glass $10 \%$ full" optimists, who look to return more survivors to productive life. ${ }^{2}$

Clinical decision rules derived over the past decade clarify when further resuscitation and transport to the hospital is futile and offer the potential to reduce ambulance transport and its inherent costs and risks. The best studied is the Basic Life Support Termination of Resuscitation (BLS-TOR) rule, which directs paramedics to stop CPR and not to transport the patient if they have not witnessed the cardiac arrest, no shock has been given (no shockable rhythm), and spontaneous circulation has not returned.

If we treat BLS-TOR as a test, a "positive" result generally predicts death, but unlike other clinical tests its specificity must be $100 \%$ because a false positive result by definition represents the wrongful death of a neurologically intact survivor of cardiac arrest. ${ }^{4}$ Validation trials of BLS-TOR have almost always found a handful of survivors who would have been declared dead by the rule. For instance, the original BLS-TOR study of 1240 cardiac arrests advised no transport for $776(63 \%)$ patients, four of whom survived to hospital discharge. ${ }^{3}$ The accuracy of paramedics applying the criteria can be problematic. In a subsequent validation study, paramedics chose to stop resuscitation in $3 \%$ of the arrests when BLS-TOR actually called for transport. ${ }^{5}$ In $15 \%$ of the cardiac arrests, trained paramedics, many of whom had participated in the original BLS-TOR derivation study, expressed discomfort about applying the rule. ${ }^{5}$ Reasons cited for disagreement included the patient's age, family distress, or short transport time to the hospital.

\section{Geographical variability in outcomes}

The quality of CPR and survival outcomes vary strikingly with geography, further complicating the application of guidelines on when to stop resuscitation. ${ }^{6}$ Studies of decision rules may report impressive positive predictive values for BLS-TOR, but a positive predictive value is not intrinsic to a test; it depends on prevalence and pretest probability. The BLS-TOR test measures futility of CPR so it naturally trends towards a higher positive predictive value in regions with poor survival outcomes for bayesian reasons. At the extreme, if you apply BLS-TOR to the late residents of Highgate cemetery, you would achieve a positive predictive value of $100 \%$. Likewise, Los Angeles has a survival rate fourfold worse than Seattle, so a higher positive predictive value for Los Angeles is expected. ${ }^{7}$ Specificity, which is independent of the population being tested, may be the more appropriate statistical measure.

Outside North America, clinical decision rules are even more fallible. BLS-TOR applied to a large Japanese validation cohort of 151152 out of hospital cardiac arrests found that specificity was only $96.8 \%$ (95\% confidence interval $96.3 \%$ to $97.2 \%$ ); the test advised stopping resuscitation for 193 people who ultimately achieved a neurologically favourable survival. ${ }^{8}$ BLS-TOR also performed poorly in a validation study in Taipei, incorrectly identifying $4.9 \%$ of 3489 patients who survived to hospital discharge as non-survivors. ${ }^{9}$ A similar study in Singapore showed specificities ranging from $81 \%$ to $91 \%$ when applied retrospectively to 2269 cardiac arrests out of hospital. ${ }^{10}$

\section{Costs of CPR survival overstated}

Cost effectiveness of CPR with respect to quality adjusted life years (QALYs) gained is about the same as that for other standard critical care therapies. For example, a study in Oslo calculated costs of $€ 40642$ ( $£ 33000 ; \$ 53000$ ) per patient discharged alive or $€ 6632$ per QALY gained. ${ }^{11}{ }^{12}$ Avoiding ambulance transport of every patient with a cardiac arrest who 
died in the emergency room would save the US Medicare programme only $\$ 58 \mathrm{~m}$, which is less than $0.1 \%$ of its total annual losses from fraud alone. ${ }^{13}$ The fear that CPR creates long term neurovegetative survivors is not borne out by the data. For the most part, patients that are destined to die do so fairly soon. ${ }^{12}$

All this effort is to what end? A modest reduction in patient transport rates? The rate of ambulance crashes with full lights and sirens is $45.9 / 100000$ patient journeys. ${ }^{2}$ We would need to halt 2178 ambulance transports to prevent a single injury, but with a false positive rate of just $1 \%$ that effort would result in more than 20 unnecessary deaths.

\section{Post-termination care and future promises}

Less tangible yet no less important considerations, such as the sentiments of the family, must be incorporated into this literally life and death process. Sudden cardiac death at home is enormously stressful for families, but ambulances in many jurisdictions will not transport dead people, leaving survivors without adequate grief counselling and logistical arrangements for autopsy, funeral, or organ donation. An estimated 5\% of all organs harvested are from legally brain dead patients who received CPR, so reducing ambulance transport of patients in cardiac arrest could diminish organ donations. ${ }^{14}$

Finally, advances in CPR research are emerging, most notably in extracorporeal cardiopulmonary resuscitation and in the regionalisation of centres that specialise in new coronary interventions and therapeutic hypothermia. ${ }^{15}$ These promising hospital based resuscitative strategies may change our definition of who is and who is not salvageable. ${ }^{16}$

\section{No-Jonathan Benger}

Cardiac arrest outside hospital is a common and catastrophic medical emergency experienced by about 60000 people a year in the UK. ${ }^{17}$ Less than $10 \%$ survive to discharge from hospital. ${ }^{18}$

The sooner spontaneous circulation returns, the better the prognosis. The chance of achieving this depends on the cause of arrest: patients with a cardiac rhythm amenable to defibrillation (ventricular fibrillation or pulseless ventricular tachycardia) have much better outlooks. ${ }^{19}$

The mainstay of treatment in all arrests is cardiopulmonary resuscitation (CPR), and international resuscitation guidelines emphasise the importance of continual and effective chest compressions, accompanied by rescue breathing. ${ }^{20}$ High quality CPR increases the chance of survival and buys time while waiting for a defibrillator or for other interventions to take effect. However, we have few other treatments. No drug has been shown to improve long term survival in patients with cardiac arrest outside hospital. ${ }^{21}$ Although many other interventions have been proposed, all lack evidence of clinical effectiveness in a general population. ${ }^{22}$

\section{Hospital has little to offer}

Ambulance services throughout the developed world tend to take patients in cardiac arrest to hospital, with CPR ongoing. This seems intuitive: these patients are critically ill, and hospital seems the obvious place to go. Indeed, when only hospital had defibrillators, the logic was clear. ${ }^{23}$ However, this is no longer the case, and hospitals have nothing to offer almost all such patients beyond the care that is provided by a well trained and equipped ambulance service. Furthermore, taking such patients to hospital may be harmful. Preparing patients for transport, moving them, and driving them to hospital leads to pauses in CPR and suboptimal chest compressions, even with the most skilled and committed staff. And it is not only the patient who is at risk: driving at speed with warning lights and sirens risks road traffic collisions that may themselves cause injury and death.

This has to stop. Ambulance clinicians are the experts in managing out of hospital cardiac arrest, and the best chance of return of spontaneous circulation, followed by long term survival, is in the first few minutes. Ambulance staff must be empowered to use their skills to optimise CPR, achieve early defibrillation, and deliver the best possible care at the scene, with no thought of transport until spontaneous circulation has returned or it becomes clear that the patient has no chance of survival. Once spontaneous circulation has returned the patient should be stabilised and transported to a "cardiac arrest centre" capable of providing coronary angiography, computed tomography, and critical care with temperature control. ${ }^{24}$ If spontaneous circulation does not return then the patient's death should be accepted and made as dignified as possible.

In rare circumstances transport to hospital with ongoing CPR is justified-for example, when cardiac arrest results from hypothermia or drug overdose and in some cases of refractory ventricular fibrillation. ${ }^{25}$ Medical advances such as out of hospital extracorporeal life support also offer hope of better survival in future. ${ }^{26}$

\section{Need for a rational approach}

This applies as much to children as it does to adults: too often the stark tragedy of a small child in cardiac arrest prompts ambulance staff to scoop up the child in arms, run to the ambulance, and drive as fast as possible to hospital. Yet this response may paradoxically deny the child the optimal chest compressions and oxygenation that he or she desperately needs and which have the greatest chance of success when delivered immediately, rather than later in the back of a moving ambulance or on arrival at hospital.

If further expertise, or transport, is deemed necessary then this should come to the patient and be delivered by a specialist team that has access to equipment such as automated chest compression devices, ultrasound and central venous access, temperature regulation, and, perhaps, extracorporeal oxygenation. This will ensure that only patients with a chance of benefiting from hospital transfer will receive it, and in a consistent way.

For the majority of patients, however, it is time to call a halt to transport in cardiac arrest and to concentrate on providing the best possible resuscitation skills at scene, empowering and supporting ambulance staff. This is not a new idea, yet little progress has been made over the past two decades. ${ }^{27} 28$ Termination of resuscitation (TOR) rules have been derived and validated in several countries ${ }^{329-31}$ and have been shown to significantly reduce the rate of futile transportation, ${ }^{32}$ yet their considerable potential has never been realised in the United Kingdom. However, TOR rules are only part of what is required: more must also be done to educate staff and the public about best possible care and what to expect when cardiac arrest occurs outside hospital - that is, excellent resuscitation undertaken at the scene (by bystanders initially and continued by the ambulance service) until spontaneous circulation returns or it becomes clear that nothing more can be done.

Competing interests: Both authors have read and understood BMJ policy on declaration of interests and have no relevant interests to declare.

Provenance and peer review: Commissioned; not externally peer reviewed. 
1 Go AS, Mozaffarian D, Roger VL, Benjamin EJ, Berry JB, Borden WB, et al. Heart disease and stroke statistics-2013 update: a report from the American Heart Association. Circulation 2013;127:e6-245.

2 Millin MG, Khandker SR, Malki A. Termination of resuscitation of nontraumatic cardiopulmonary arrest: resource document for the National Association of EMS Physicians position statement. Prehosp Emerg Care 2011;15:547-54.

3 Morrison LJ, Visentin LM, Kiss A, Theriault R, Eby D, Vermeulen M, et al. Validation of a rule for termination of resuscitation in out-of-hospital cardiac arrest. N Engl J Med 2006;355:478-87.

4 Sherbino J, Keim SM, Davis DP, Best Evidence In Emergency Medicine (BEEM) Group. Clinical decision rules for termination of resuscitation in out-of-hospital cardiac arrest. $J$ Emerg Med 2010;38:80-6.

5 Morrison LJ, Visentin LM, Vermeulen M, Kiss A, Theriault R, Eby D, et al. Inter-rater reliability and comfort in the application of a basic life support termination of resuscitation clinical prediction rule for out of hospital cardiac arrest. Resuscitation 2007;74:150-7.

6 Nichol G, Thomas E, Callaway CW, Hedges J, Powell JL, Aufderheide TP, et al. Regional variation in out-of-hospital cardiac arrest incidence and outcome. JAMA 2008;300:1423-31. Eckstein M, Stratton SJ, Chan LS. Cardiac arrest resuscitation evaluation in Los Angeles: CARE-LA. Ann Emerg Med 2005;45:504-9.

8 Kajino K, Kitamura T, Iwami T, Daya M, Hock Ong ME, Hiraide A, et al. Current termination of resuscitation (TOR) guidelines predict neurologically favorable outcome in Japan. Resuscitation 2013;84:54-9.

9 Chiang W-C, Ko PC-I, Chang AM, Liu SS-H, Wang H-C, Yang C-W, et al. Predictive performance of universal termination of resuscitation rules in an Asian community: are they accurate enough? Emerg Med J 2013.

10 Ong ME Tan EH, Ng FS, Yap S, Panchalingham A, Leong BS- $\mathrm{H}$, et al Comparison of termination-of-resuscitation guidelines for out-of-hospital cardiac arrest in Singapore EMS. Resuscitation 2007:75:244-51.

11 Edbrooke DL, Minelli C, Mills GH, lapichino G, Pezzi A, Corbella D,et al. Implications of ICU triage decisions on patient mortality: a cost-effectiveness analysis. Crit Care 2011;15:R56

12 Naess AC, Steen PA. Long term survival and costs per life year gained after out-of-hospital cardiac arrest. Resuscitation 2004;60:57-64.

13 Suchard JR, Fenton FR, Powers RD. Medicare expenditures on unsuccessfu out-of-hospital resuscitations. J Emerg Med 1999;17:801-5.

14 Orioles A, Morrison WE, Rossano JW, Shore PM, Hasz RD, Martiner AC, et al. An under-recognized benefit of cardiopulmonary resuscitation: organ transplantation. Crit Care Med 2013;41:2794-9.

15 Müller T, Lubnow M. The future of E-CPR: A joint venture. Resuscitation 2013:84:1463-4

16 Nichol G, Aufderheide TP, Eigel B, Neumar RW, Lurie KG, Bufalino VJ, et al. Regional systems of care for out-of-hospital cardiac arrest: a policy statement from the American Heart Association.[Erratum appears in Circulation 2010;122:e439]. Circulation 2010;121:709-29.

17 Berdowski J, Berg RA, Tijssen JG, Koster RW. Global incidences of out-of-hospital cardiac arrest and survival rates: systematic review of 67 prospective studies. Resuscitation 2010;81:1479-87.
18 Perkins GD, Cooke MW. Variability in cardiac arrest survival: the NHS Ambulance Service quality indicators. Emerg Med J 2012;29:3-4.

19 Herlitz J, Svensoon L, Engdahl J, Silfverstolpe J. Characteristics and outcome in out-of-hospital cardiac arrest when patients are found in a non-shockable rhythm. Resuscitation 2008;76:31-6.

20 Nolan JP, Hazinski MF, Billi JE, Bottiger BW, Bossaert L, de Caen AR, et al. Part 1 : executive summary: 2010 international consensus on cardiopulmonary resuscitation and emergency cardiovascular care science with treatment recommendations. Resuscitation 2010;81(suppl 1):e1-25.

21 Jacobs IG, Finn JC, Jelinek GA, Oxer HF, Thompson PL. Effect of adrenaline on survival in out-of-hospital cardiac arrest: a randomised double-blind placebo-controlled trial. Resuscitation 2011;82:1138-43.

22 Stiell IG, Wells GA, Field B, Spaite DW, Nesbitt LP, De Maio VJ, et al. Advanced cardiac life support in out-of-hospital cardiac arrest. N Engl J Med 2004;351:647-56.

23 Zoll PM, Linenthal AJ, Gibson W, Paul MH, Norman. Termination of ventricular fibrillation in man by externally applied electric countershock. N Engl J Med 1956;254:727-32.

24 Tagami T, Hirata K, Takeshige T, Matsui J, Takinami M, Satake M, et al. Implementation of the fifth link of the chain of survival concept for out-of-hospital cardiac arrest. Circulation 2012;126:589-97.

25 Gilbert M, Busund R, Skagseth A, Nilsen PA, Solbø JP. Resuscitation from accidental hypothermia of $13.7^{\circ} \mathrm{C}$ with circulatory arrest. Lancet 2000;355:375-6.

26 Arlt M, Philipp A, Voelkel S, Graf BM, Schmid C, Hilker M. Out-of-hospital extracorporeal life support for cardiac arrest-a case report. Resuscitation 2011;82:1243-5.

27 Bonnin MJ, Pepe PE, Kimball KT, Clark PS Jr. Distinct criteria for termination of resuscitation in the out-of-hospital setting. JAMA 1993;270:1457-62.

28 Kellermann AL, Hackman BB, Somes G. Predicting the outcome of unsuccessful prehospital advanced cardiac life support. JAMA 1993;270:1433-6.

29 Verbeek PR, Vermeulen MJ, Ali FH, Messenger DW, Summers J, Morrison LJ. Derivation of a termination-of-resuscitation guideline for emergency medical technicians using automated external defibrillators. Acad Emerg Med 2002;9:671-8.

30 Morrison LJ, Verbeek PR, Vermeulen MJ, Kiss A, Allan KS, Nesbitt L, et al. Derivation and evaluation of a termination of resuscitation clinical prediction rule for advanced life support providers. Resuscitation 2007;74:266-75

31 Morrison LJ, Verbeek PR, Zhan C, Kiss A, Allan KS. Validation of a universal prehospital termination of resuscitation clinical prediction rule for advanced and basic life support providers. Resuscitation 2009;80:324-8.

32 Morrison LJ, Eby D, Veigas PV, Zhan C, Kiss A, Arcieri V, et al. Implementation trial of the basic life support termination of resuscitation rule: reducing the transport of futile out-of-hospital cardiac arrests. Resuscitation 2014;85:486-91.

Cite this as: BMJ 2014;349:g5659

(c) BMJ Publishing Group Ltd 2014 